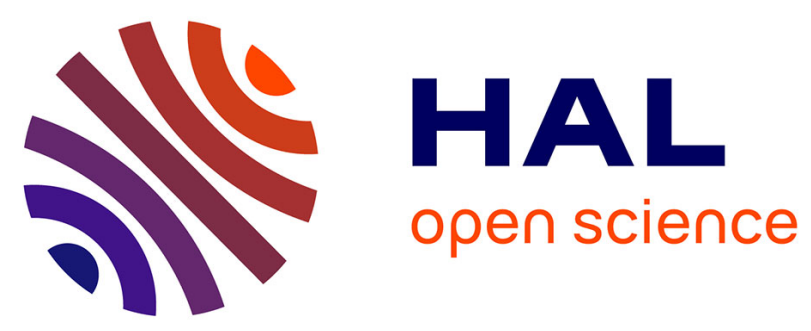

\title{
Regionalized Random Germs by a Classification for Probabilistic Watershed Application: Angiogenesis Imaging Segmentation
}

\author{
Guillaume Noyel, Jesus Angulo, Dominique Jeulin
}

\section{- To cite this version:}

Guillaume Noyel, Jesus Angulo, Dominique Jeulin. Regionalized Random Germs by a Classification for Probabilistic Watershed Application: Angiogenesis Imaging Segmentation. Alistair D. Fitt, John Norbury, Hilary Ockendon, and Eddie Wilson. Progress in Industrial Mathematics at ECMI 2008, Springer, pp.211-216, 2010, Mathematics in Industry, 978-3-642-12109-8. 10.1007/978-3-642-121104_29. hal-00834452

HAL Id: hal-00834452

https://hal-mines-paristech.archives-ouvertes.fr/hal-00834452

Submitted on 15 Jun 2013

HAL is a multi-disciplinary open access archive for the deposit and dissemination of scientific research documents, whether they are published or not. The documents may come from teaching and research institutions in France or abroad, or from public or private research centers.
L'archive ouverte pluridisciplinaire HAL, est destinée au dépôt et à la diffusion de documents scientifiques de niveau recherche, publiés ou non, émanant des établissements d'enseignement et de recherche français ou étrangers, des laboratoires publics ou privés.

$$
\text { Copyright }
$$




\section{Regionalized random germs by a classification for probabilistic watershed. Application: angiogenesis imaging segmentation}

Guillaume Noyel, Jesús Angulo, and Dominique Jeulin

MINES ParisTech, CMM - Centre de Morphologie Mathématique, Mathématiques et Systèmes, 35 rue Saint Honoré - 77305 Fontainebleau cedex, France

\{noyel, angulo, jeulin\}@cmm.ensmp.fr

Summary. New methods are presented to generate random germs regionalized by a previous classification in order to use probabilistic watershed on hyperspectral images. These germs are much more efficient than the standard uniform random germs.

\section{Introduction}

Probabilistic watershed was introduced by Angulo and Jeulin [1] to detect the contours of the widest and the most contrasted regions in images. The obtained contours are more regular and significant than these associated to the deterministic watershed. Probabilistic watershed was then extended to hyperspectral images by Noyel, Angulo and Jeulin [5].

The standard stochastic WS consists in starting from uniform random points germs as sources to flood the norm of a gradient in order to obtain the associated contours. After repeating the process a large number of times, a probability density function of contours (pdf) is computed by the Parzen kernel method [1]. The pdf is segmented by a hierarchical watershed according to a morphological criterion such as the volume (i.e. integral of intensities) [3]. For hyperspectral images, a pdf is built for each channel of the image and the flooding function is the weighted sum of the pdf of the channels. This function, called a marginal probability density function, is based on spatial information [5].

As, for hyperspectral images, a spectral classification can be computed $[4,6]$, it is interesting to estimate the marginal pdf $m p d f$ conditionally to this previous spectral classification [6]. Therefore, this pdf represents jointly spatio-spectral information.

In the sequel, after presenting the results obtained using uniform random germs, we compare several approaches to compute random germs regionalized by a previous classification. 


\section{Pre-requisites}

Our results are presented on a medical image of DCE-MRI series (Dynamic Contrasted Enhanced Magnetic Resonance Imaging) of mice. The image is a series of 512 channels of size $128 \times 128$ acquired at a regular step of 1 second, in time, on mice presenting tumors [2]. This image is filtered and represented in a parameter space $\mathbf{p}$ of a smaller dimension [6]. A marginal pdf is built in this space. The pdf is segmented by a hierarchical watershed according to a volume criterion in 20 or 30 regions. An external marker is added during the computation of the pdf. The results of the segmentation are presented on a channel of the image space $\mathbf{f}_{\lambda}$. In the figure 1 , we notice that the pdf $m p d f\left(\mathbf{p}, m r k_{i}\right)$ presents a lot of contours on the background of the image. Therefore the image segmentation, $s g_{R}^{v o l}\left(m p d f\left(\mathbf{p}, m r k_{i}\right)\right)$, leads to an over-segmentation especially in the background.

In fact, for images presenting wide and low contrasted regions, several germs (or markers) may fall in these regions during the pdf estimation with uniform random germs. These uniform random germs create artificial contours that do not corresponds to relevant contours.

That is the reason why random germs regionalized by a previous classification are introduced. In order to do this, random germs are drawn in the classes of the classification. However, to avoid that a germ may fall on the boundary of a class, that would lead to a leak during the flooding process of the watershed on the pdf, each class of the classification $\kappa$ is reduced by an erosion (i.e. an anti-extensive transformation) with a square structuring element (s.e.) with size $3 \times 3$ pixels. Therefore a new void class is introduced. Moreover the holes in each class are filled by a closing by reconstruction (s.e. $3 \times 3$ pixels). After this morphological transformation, the classes are re-labelled with a different label for each connected class. The transformed classification is written $\widehat{\kappa}$ and named pre-segmentation (fig. 1 top). It is composed of connected classes, $\widehat{\kappa}=\cup_{k} C_{k}$ with $\cap C_{k}=\emptyset$. The void class is written $C_{0}$.

\section{Random points-germs regionalized by a classification}

Uniform random germs are drawn on the pre-segmentation $\widehat{\kappa}$. If a germ falls in a connected class $C_{k}$ not yet marked by a previous germ, $k \neq 0$, then it is kept otherwise it is rejected. As we have a pre-segmentation $\widehat{\kappa}$, we use it to detect the background of the image by preventing germs from falling into the background class (algorithm 1). Therefore not all the germs are kept.

We notice that the resulting segmentations $\operatorname{sg}_{R}^{v o l}\left(m p d f\left(\mathbf{p}, m r k_{i}^{\kappa-p t}\right)\right)$ are much better than with uniform random germs $s g_{R}^{v o l}\left(m p d f\left(\mathbf{p}, m r k_{i}\right)\right)$ (fig. 1). 


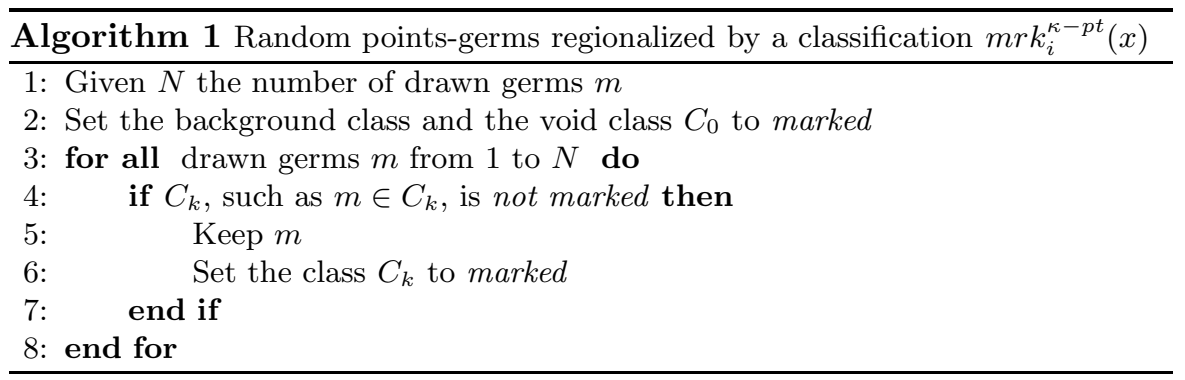

\section{Random balls-germs regionalized by a classification}

One of the drawback of the point germs is to enhance the contours of the small regions. With larger germs the probability of the small contours decreases. To obtain random balls germs $B(m, r)$, the centers $m$ of the balls are drawn according to a rule. If the center is kept, a random radius $r$ is drawn in the interval ]0, Rmax].

\subsection{Each connected class may be hit one time}

The centers $m$ of the balls are drawn as random points-germs regionalized by the pre-segmentation $\widehat{\kappa}$. Only the intersection between the ball $B(m, r)$ and the connected class $C_{k}$, such as $m \in C_{k}$, is kept as a germ. We notice that each connected class may be hit one time (algorithm 2). The segmentations are a bit better than with regionalized random points germs $m r k_{i}^{\kappa-p t}(x)$ (fig. $1)$.

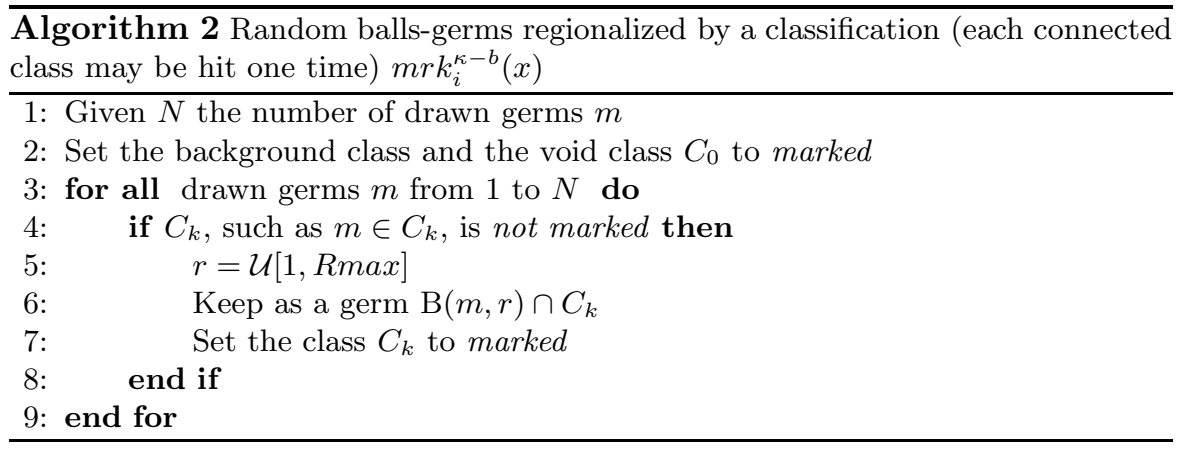

When a class can only be hit one time, the drawback is that only a small number of germs are effectively implanted: for $N=100$ germs, only an average of 6 are really implanted. 


\subsection{Each connected class may be hit several times}

Increasing the number of really implanted germs leads to a better detection of contours thanks to larger markers in each class. That is the reason why we introduce the possibility that several germs may fall in the same connected class.

\section{Union of germs in each connected class}

When several random balls germs fall in the same connected class $C_{k}$, their intersection is made with the class $C_{k}$. Then their union is made to obtain the germ of the class (alg. 3).

In figure 1, the regions of the segmentations $s g_{R}^{v o l}\left(m p d f\left(\mathbf{p}, m r k_{i}^{\kappa-\cup b}\right)\right)$ are almost the same whatever the number of regions $R$ are.

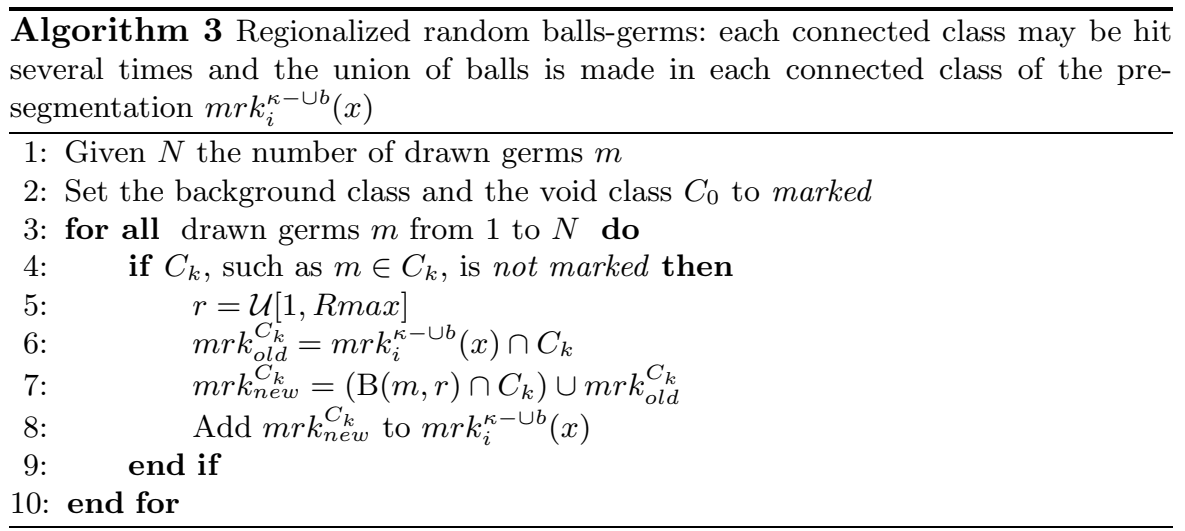

\section{Union of connected germs in each connected class}

As for the previous germs, when several random balls germs fall in the same connected class $C_{k}$, their intersection is made with the class $C_{k}$. Then the union of the connected germs is made to obtain one of the germs of the class (alg. 4).

We notice that the resulting segmentations may be a bit over-segmented $s g_{R}^{v o l}\left(m p d f\left(\mathbf{p}, m r k_{i}^{\kappa-\cup b-c x}\right)\right)$ (fig. 1). It can be useful to make a thinner analysis of each region.

\section{Conclusion}

We have shown that using regionalized random germs by a classification is better than using uniform random germs in order to segment by means 


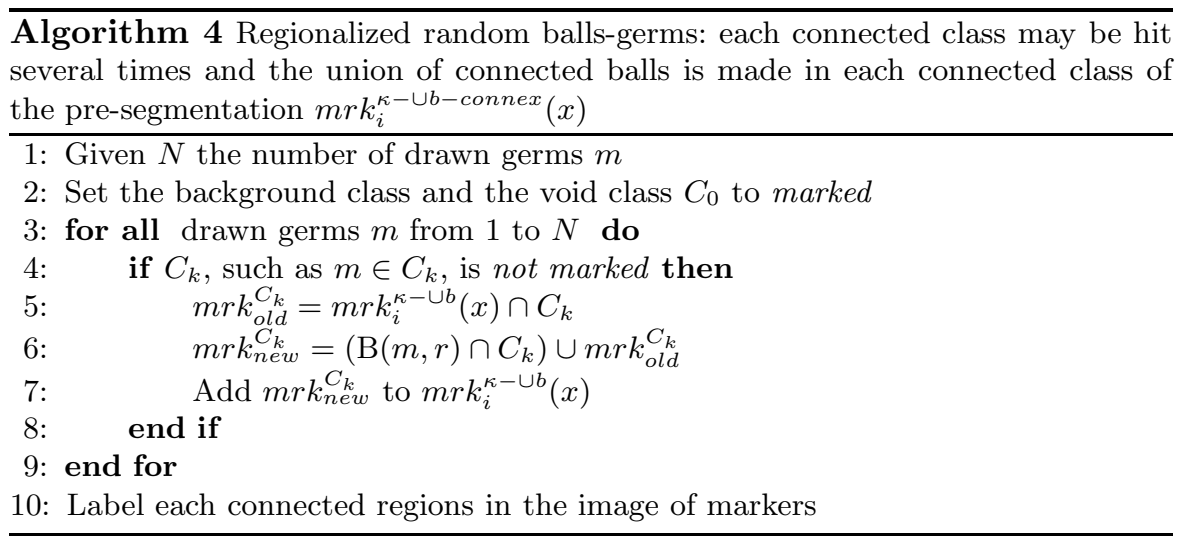

of the probabilistic watershed. Moreover, the segmentations, in which all the germs fallen in a connected region of the pre-segmentation $\widehat{\kappa}$ have the same label, have generally correct contours $s g_{R}^{v o l}\left(m p d f\left(\mathbf{p}, m r k_{i}^{\kappa-p t}\right)\right)$ $s g_{R}^{v o l}\left(m p d f\left(\mathbf{p}, m r k_{i}^{\kappa-b}\right)\right), s g_{R}^{v o l}\left(m p d f\left(\mathbf{p}, m r k_{i}^{\kappa-\cup b}\right)\right)$. When there may be several germs in a connected region, $s g_{R}^{v o l}\left(m p d f\left(\mathbf{p}, m r k_{i}^{\kappa-\cup b-c x}\right)\right)$, the image is over-segmented and it can be useful to make a thinner analysis of the segmented regions $[6]$.

Acknowledgements: The authors are indebted to Pr. C.A. Cuenod (Hôpital Européen G. Pompidou, Paris, France) for providing the MRI images.

\section{References}

1. J. Angulo and D. Jeulin. Stochastic watershed segmentation. In G. Banon et al., editor, Proc. of the 8th Int. Symposium on Mathematical Morphology, volume 1, pages 265-276. Instituto Nacional de Pesquisas Espaciais (INPE), 2007.

2. D. Balvay, F. Frouin, G. Calmon, B. Bessoud, E. Kahn, N. Siauve, O. Clément, and C.A. Cuenod. New criteria for assessing fit quality in dynamic contrastenhanced $T_{1}$-weighted MRI for perfusion and permeability imaging. Magnetic Resonance in Medicine, 54:868-877, 2005.

3. F. Meyer. An overview of morphological segmentation. International Journal of Pattern Recognition and Artificial Intelligence, 15(7):1089-1118, 2001.

4. G. Noyel, J. Angulo, and D. Jeulin. Morphological segmentation of hyperspectral images. Image Analysis and Stereology, 26:101-109, November 2007.

5. G. Noyel, J. Angulo, and D. Jeulin. Random germs and stochastic watershed for unsupervised multispectral image segmentation. In B. Apolloni et al., editor, KES 2007/ WIRN 2007, volume III of LNAI 4694, pages 17-24. KnowledgeBased Intelligent Information and Engineering Systems, Springer-Verlag, 2007.

6. G. Noyel, J. Angulo, and D. Jeulin. Filtering, segmentation and region classification by hyperspectral mathematical morphology of DCE-MRI series for angiogenesis imaging. In Proc. IEEE International Symposium on Biomedical Imaging ISBI 2008, pages 1517-1520, 2008. 


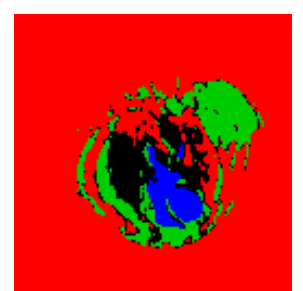

$\kappa$

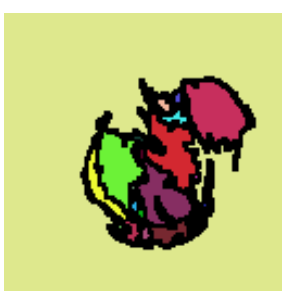

$\widehat{\kappa}$

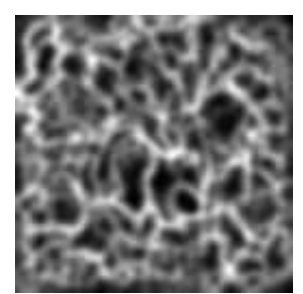

$\operatorname{mpdf}\left(\mathbf{p}, m r k_{i}\right)$

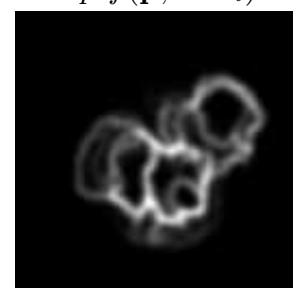

$\operatorname{mpdf}\left(\mathbf{p}, m r k_{i}^{\kappa-p t}\right)$

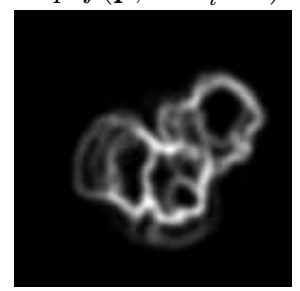

$m p d f\left(\mathbf{p}, m r k_{i}^{\kappa-b}\right)$

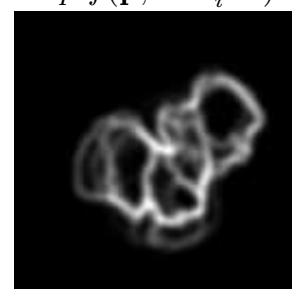

$\operatorname{mpdf}\left(\mathbf{p}, m r k_{i}^{\kappa-\cup b}\right)$

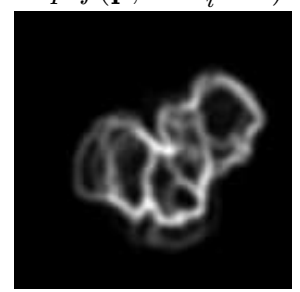

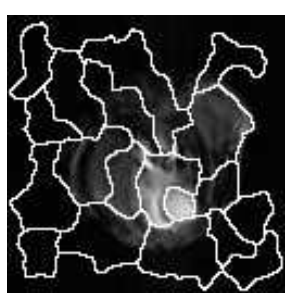

$s g_{R=20}^{v o l}\left(\operatorname{mpdf}\left(\mathbf{p}, m r k_{i}\right)\right)$

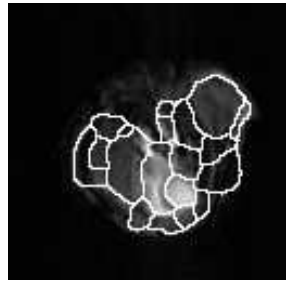

$s g_{R=20}^{v o l}\left(m p d f\left(\mathbf{p}, m r k_{i}^{\kappa-p t}\right)\right)$

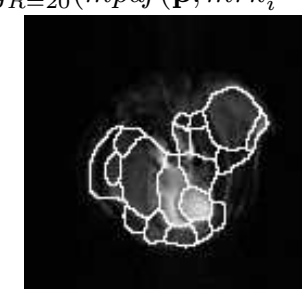

$s g_{R=20}^{v o l}\left(\operatorname{mpdf}\left(\mathbf{p}, m r k_{i}^{\kappa-b}\right)\right)$

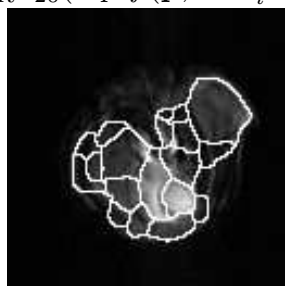

$s g_{R=20}^{v o l}\left(m p d f\left(\mathbf{p}, m r k_{i}^{\kappa-\cup b}\right)\right)$

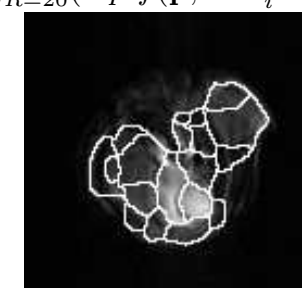

$m p d f\left(\mathbf{p}, m r k_{i}^{\kappa-\cup b-c x}\right) s g_{R=20}^{v o l}\left(m p d f\left(\mathbf{p}, m r k_{i}^{\kappa-\cup b-c x}\right)\right) s g_{R=30}^{v o l}\left(m p d f\left(\mathbf{p}, m r k_{i}^{\kappa-\cup b-c x}\right)\right)$
Fig. 1. Top: classification $\kappa$ by LDA in 4 classes in parameters space and its trans-

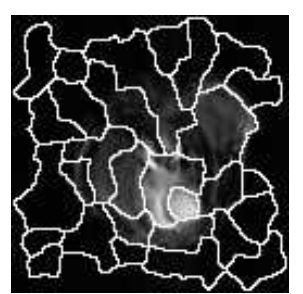

$s g_{R=30}^{v o l}\left(m p d f\left(\mathbf{p}, m r k_{i}\right)\right)$

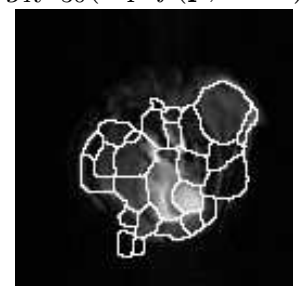

$s g_{R=30}^{v o l}\left(\operatorname{mpdf}\left(\mathbf{p}, m r k_{i}^{\kappa-p t}\right)\right)$

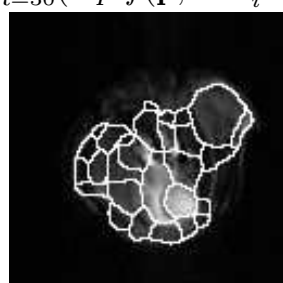

$s g_{R=30}^{v o l}\left(\operatorname{mpdf}\left(\mathbf{p}, m r k_{i}^{\kappa-b}\right)\right)$

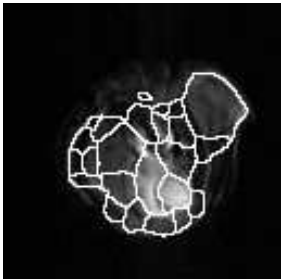

$s g_{R=30}^{v o l}\left(m p d f\left(\mathbf{p}, m r k_{i}^{\kappa-\cup b}\right)\right)$

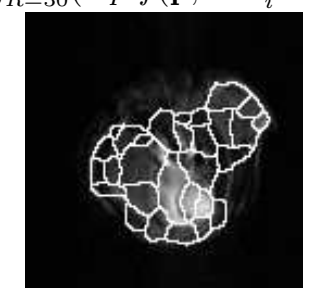

$\operatorname{mpdf}\left(\mathbf{p}, m r k_{i}^{\kappa-\cup b-c x}\right) s g_{R=20}^{v o l}\left(\operatorname{mpdf}\left(\mathbf{p}, m r k_{i}^{\kappa-\cup b-c x}\right)\right) s g_{R=30}^{v o l}\left(m p d f\left(\mathbf{p}, m r k_{i}^{\kappa-\cup b-c x}\right)\right)$
Fig. 1. Top: classification $\kappa$ by LDA in 4 classes in parameters space and its transformed classification (or pre-segmentation) $\widehat{\kappa}$. Bottom: marginal pdf $m p d f$ for several kinds of germs and associated segmentations by a volumic watershed. 